\title{
An International Expert Survey on Functioning in Vocational Rehabilitation Using the International Classification of Functioning, Disability and Health
}

\author{
Reuben Escorpizo - Monika E. Finger • \\ Andrea Glässel · Alarcos Cieza
}

Published online: 9 December 2010

(C) Springer Science+Business Media, LLC 2010

\begin{abstract}
Background Vocational rehabilitation (VR) is a key process in work disability (WD) management which aims to engage or re-engage individuals to work and employment. The International Classification of Functioning, Disability and Health (ICF) by the World Health Organization (WHO) can be interfaced with VR but there is a lack of evidence of what ICF contents experts in the field consider. The objective of this study is to survey the experts in the VR field with regard to what factors are considered important to patients participating in VR using the ICF as the language to summarize the results. Methods An internet-based survey was conducted with experts from
\end{abstract}

R. Escorpizo ( $\square)$ · M. E. Finger · A. Glässel · A. Cieza Swiss Paraplegic Research (SPF), Guido A. Zäch Str. 4, 6207 Nottwil, Switzerland

e-mail: reuben.escorpizo@paranet.ch

R. Escorpizo · M. E. Finger · A. Glässel · A. Cieza ICF Research Branch of WHO Collaborating Centre for the Family of International Classifications in German, Nottwil, Switzerland

\section{A. Cieza}

ICF Research Branch of WHO Collaborating Centre for the Family of International Classifications in German, Munich, Germany

M. E. Finger

Rehaklinik Bellikon, Bellikon, Switzerland

\section{A. Cieza}

Institute for Health and Rehabilitation Sciences, Research Unit for Biopsychosocial Health, Ludwig-Maximilians Universität, Munich, Germany

R. Escorpizo

Department of Health Sciences and Health Policy, University of Lucerne, Nottwil, Switzerland six WHO Regions (Africa, the Americas, Eastern Mediterranean, Europe, South-East Asia, and Western Pacific). Experts were asked six open-ended questions on factors that are important in VR. Each question was related to a component of the ICF (body functions, body structures, activities and, environmental factors, and personal factors). Responses were linked to the ICF. Results Using a modified stratified randomized sampling, 201 experts were sent the survey and 151 experts responded (75\% response rate). We identified 101 ICF categories: $22(21.8 \%)$ for body functions, 13 (12.9\%) for body structures, 36 (35.6\%) for activities and participation, and 30 (29.7\%) for environmental factors. Conclusions There was a multitude of ICF functioning domains according to the respondents which indicates the complexity of VR. This expert survey has provided a list of ICF categories which could be considered in VR.

Keywords ICF · Vocational rehabilitation - Survey · Expert · Work · Employment

\section{Introduction}

Work disability (WD) may occur as a result of a health condition or a health-related event and the associated burden may be evident at the individual level and the society level. This burden may appear in the form of consequences of limited or restricted work participation. Vocational rehab (VR) is a key process in WD management which aims to engage or re-engage individuals back to work and employment and has been documented in the literature to be effective in addressing WD issues [1-6].

The International Classification of Functioning, Disability and Health [7] is a generic conceptual framework 
and classification system of the World Health Organization (WHO) that can be actively interfaced with VR or within the context of return-to-work, or work participation [8-11]. As a conceptual model, the ICF recognizes that functioning and disability is a result of the interaction between components: body functions (b), body structures (s), activities and participation $(d)$, environmental factors $(e)$, and personal factors (not coded). As a classification system, the ICF can serve as a basis for evaluating the scope and complexity of VR services by providing a comprehensive list of functioning domains in the form of alphanumeric coded ICF categories that are arranged in a hierarchical fashion, hence different levels, for each of the ICF categories or functioning domains. Below is an illustration of this categorization:

\begin{tabular}{ll}
\hline ICF component & $\mathrm{d}$ activities and participation \\
Chapter & $\mathrm{d} 4$ Mobility \\
Second-level category & $\mathrm{d} 430$ Lifting and carrying objects \\
Third-level category & $\mathrm{d} 4300$ Lifting \\
\hline
\end{tabular}

However, there remains a lack of understanding of functioning within VR in terms of the ICF, despite the need for VR providers to understand the broad range of functioning factors (instead of being too focused) to improve work disability outcomes in the clinical setting or community-based setting in VR. Therefore, the objective of this study is to survey the experts in the VR field regarding what factors are important to individuals participating in VR using the ICF as the language to summarize the results.

\section{Materials and Method}

\section{Recruitment of Experts}

A survey was conducted over the internet with expert participants from six WHO Regions (Africa, the Americas, Eastern Mediterranean, Europe, South-East Asia, and Western Pacific). An "expert" was arbitrarily defined to have at least 2 years of relevant experience (practice, research, or both) in the field of VR, may be a health professional, and is able to communicate competently in English [12]. A procedure using Secure Sockets Layer, 128-bit encryption technology ensured the security and privacy of the web-based survey.

Invitations to the experts were sent out via secure electronic e-mail. E-mail addresses of experts were obtained from literature search (through a concurrent systematic review), internet search, professional organizations, journal editorial board, informal networks, and peers. An expert who was contacted was also asked to name and refer other experts.

Recruitment of experts into the "pool" was performed from March to June 2009. Selection of experts from this pool who were to complete the survey was done using randomized stratified sampling. This sampling method was modified so that at least one expert from each country is included. This modification was made to ensure that all the countries in the pool are represented.

\section{Information from the Experts}

Sociodemographic information was collected from the sampled experts. Information included country, age, sex, profession, main field of practice ( $>50 \%$ of the time), years of experience in VR, whether they are a direct healthcare provider, primary type of patients they deal with, and types of VR services they are involved with. Experts were also asked to self-rate based on an 11-point numerical scale regarding their expertise in VR (from $0=$ "No experience" to $10=$ "Excellent experience").

\section{Survey Website and Survey Questions}

The survey was conducted in English. The initial part of the survey asked the respondents information on sociodemographics and their experience in VR. For the main part of the survey, experts were asked with six open-ended questions (see Table 1) to examine which factors they consider relevant and important to individuals who participate in a VR program. Each question is related to a component of the ICF (body functions, body structures, activities and participation, environmental factors, and personal factors). For example, the first question on "body and mind" is related to the ICF component of body functions. Experts, however, did not see the ICF component labels embedded in the questions. Blank fields for the answers were provided after each question and respondents were allowed to provide multiple answers. Answers were not limited in terms of word length although respondents were instructed to be brief and concise and avoid abbreviations and vague technical terms. The expected completion time for the survey was $30 \mathrm{~min}$.

\section{Linking to the ICF}

All responses gathered from the experts were linked to the ICF applying published linking rules [13]. The objective of the linking process is to be able to translate the concepts found in the experts' responses into the most fitting ICF categories. Two individuals who are trained and 
Table 1 ICF-based questions that the experts were asked. The ICF component indicated within the brackets were not seen by the participants

1. If you think about the body and mind of individuals participating in vocational rehabilitation, list (function) problems that are relevant to them? (Body functions)

2. If you think about the body parts of individuals participating in vocational rehabilitation, which body parts are their problems? (Body structures)

3. If you think about the daily life activities and involvement in the society of individuals participating in vocational rehabilitation, what are their problems? (Activities and participation)

4. If you think about the environment and the living conditions of individuals participating in vocational rehabilitation, what is hindering (barrier) for them? (Environmental factors-barriers)

5. If you think about the environment and the living conditions of individuals participating in vocational rehabilitation, what is helpful (facilitator) for them? (Environmental factors-facilitators)

6. If you think about individuals participating in vocational rehabilitation, what personal characteristics are important to the way they handle their situation? (Personal factors)

experienced in the linking process, independently linked the responses. The first linker (L1) linked $100 \%$ of the responses, while the second linker (L2) counter-linked 33\% randomly selected concepts of $\mathrm{L} 1$. If there was a disagreement between L1 and L2 with the counter-linked concepts, both tried to resolve the disagreement between them, otherwise a third person was consulted.

The ICF categories that were identified based on the experts' responses were listed and a frequency analysis was performed.

\section{Reliability of Linking}

To evaluate the reliability of the linking process, the overall percentage of agreement was calculated based on the two independent linkage versions. In addition, to examine the extent to which the achieved agreement exceeds chance, the Kappa coefficient [14] and nonparametric bootstrapped confidence interval $[15,16]$ were calculated. We performed Kappa analysis using SAS software version 9.1 (Copyright (C) 2002-2003 by SAS Institute Inc., Cary, NC, USA).

\section{Results}

\section{Recruitment of Experts}

There were 626 experts recruited into the pool who were identified from our search and were invited to have their names in the pool. Out of the 626 experts, 295 (47\%) from 47 countries agreed to be in the pool. After a modified stratified randomized sampling (profession $\times$ WHO region $\times$ country), 201 experts were selected to whom the survey was sent. In total, we received responses from 151 experts (75\% response rate). Electronic reminders (i.e. e-mail) were sent to the experts twice in regular interval to encourage participation.

\section{Characteristics of Expert Respondents}

Sociodemographics of the respondents and their self-rating of expertise are presented in Table 2. About one-third of the respondents belonged to the 41-50 year-old age range; nearly half of them were male, a little over a third were from Europe, close to two-thirds of the sample were physical and occupational therapists, and most respondents were engaged in clinical or research work. A majority of the respondents $(>85 \%)$ had at least 8 years of experience in the field of VR and have rated themselves at least 7 out of 10 in the "expertise scale" of 0-10 with number close to 10 meaning greater expertise. About half of the respondents directly provide healthcare service to patients and close to $65 \%$ conducts their work on patients with musculoskeletal health conditions. Looking at the specific types of VR services that the respondents provide or are engaged with in research, we found a broad variety of those services (Table 2).

\section{Description of Responses and ICF Categories}

Based on the responses generated from the survey, most of the respondents provided topical words and phrases. Mean time spent to complete the survey for 128 respondents was $29 \mathrm{~min}$ and $30 \mathrm{~s}$ (median $=21 \mathrm{~min}$ and $22 \mathrm{~s}$ ). Completion time for the rest of the experts was excluded because they either took multiple days or longer than $8 \mathrm{~h}$ to complete the survey. The survey platform was configured to allow them to answer parts of the survey in different times. This means that a respondent may start answering a few questions today and then complete the survey tomorrow, so that will indicate more than $24 \mathrm{~h}$ of survey completion when in reality it was probably just $30 \mathrm{~min}$ in total.

One hundred one second-level ICF categories were identified based on the ICF-linked responses of the experts. Only those that were stated by at least 5\% (arbitrary decision) of the respondents were included. Out of these 101 categories, $22(21.8 \%)$ were related to body functions 
Table 2 Demographics and VR experience of experts surveyed (percentage of $\mathrm{n}=151$ expert respondents)

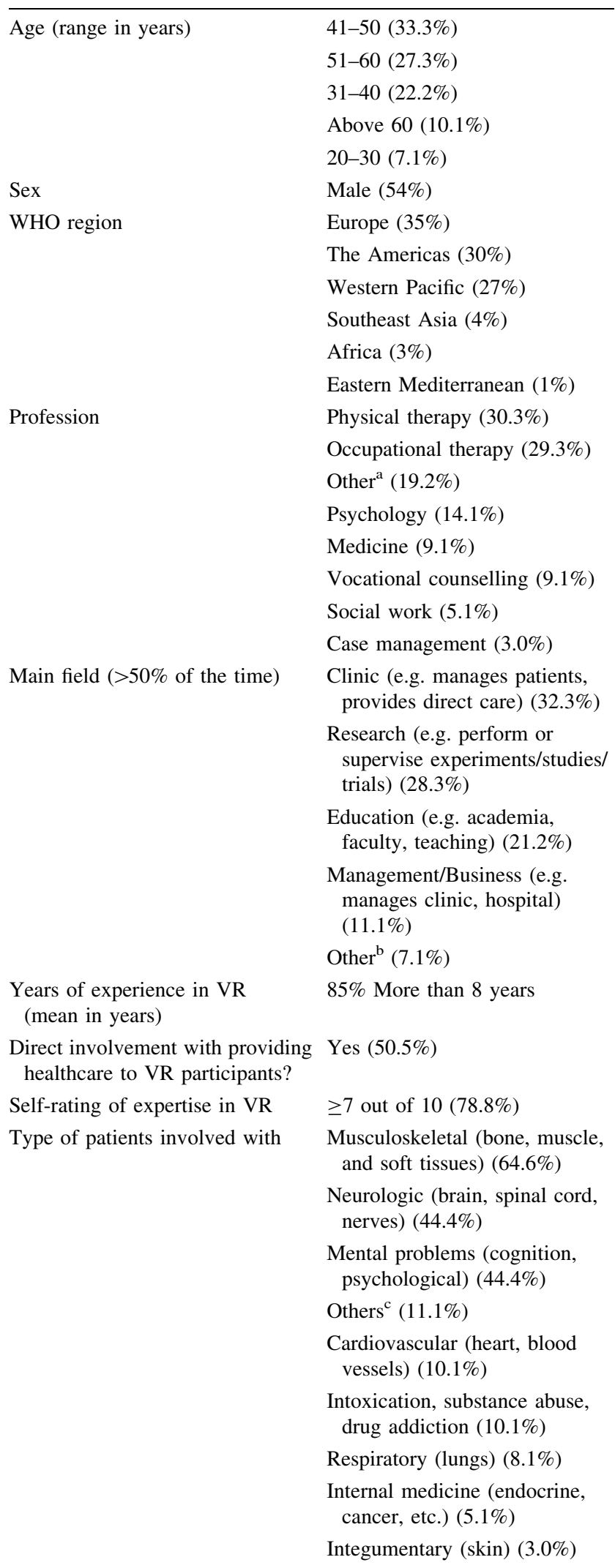

Table 2 continued

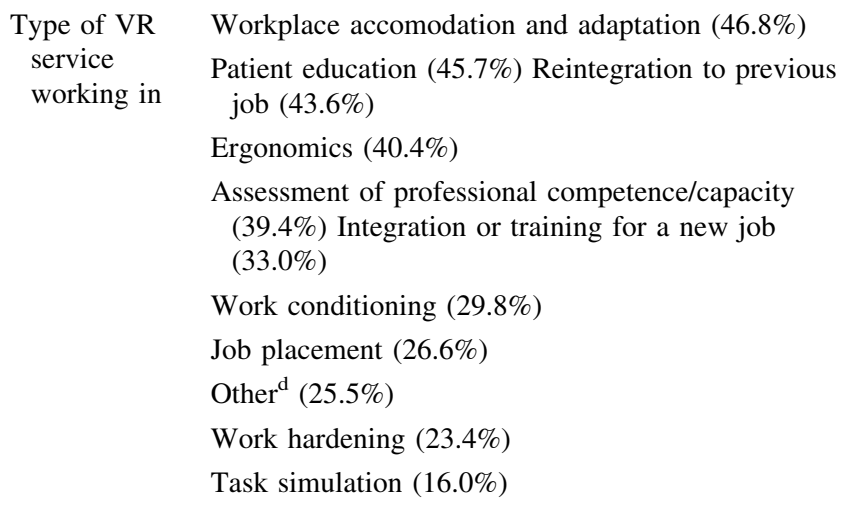

a Other: Teaching/education, rehabilitation counselling, massage therapy, movement science, pedagogy, rehabilitation science, psychotherapy, rehabilitation psychology, podiatry, sociology, art history and geography, ergonomics, health promotion and health education, public health, labour/health economics, special education

b Other: Clinic consultation, medical legal consultation, editorship, community rehabilitation consultation, medico-legal private practice, caregiver and client training, work/home case management

c Other: "Don't see clients", burn, orthopaedics, psychiatry, education, functional cognition, hearing and seeing impairment, developmental disability

d Other: Quality assurance, management, job trials, functional capacity evaluation, injury prevention, "direct care", group therapy, neurological rehabilitation, workplace rules training, role training, workplace behaviour, consultation/supervision, income benefits training, disclosure counselling, collaborative assessment, supported employment, litigation, family and employer education, soft tissue manipulation, referral to networks, functional cognition assessment, case management, editorship

(Table 3), $13(12.9 \%)$ were related to body structures (Table 4), $36(35.6 \%)$ were related to activities and participation (Table 5), and 30 (29.7\%) were related to environmental factors (Table 6).

Our reliability calculation between linkers (researchers) at the second-level ICF categories resulted in an overall percentage agreement of $61.7 \%$, an estimated 0.61 Kappa coefficient, and a confidence interval (bias corrected percentile method) of $0.58-0.63$. For the third-level categories, the overall percentage agreement was $56.0 \%$, estimated 0.55 Kappa coefficient, and a confidence interval (bias corrected percentile method) of $0.53-0.58$.

\section{Discussion}

VR is a key process that enables individuals to participate in or return back to gainful employment. VR, as a component of work disability management, covers a wide variety of factors. In this study, we used the ICF as a conceptual framework and classification system to explore 
Table 3 Body functions $(\mathrm{N}=22)$ (included were only those categories mentioned by at least $5 \%$ of the respondents)

\begin{tabular}{lll}
\hline ICF code & Title & Percentage (\%) \\
\hline b126 & Temperament and personality function & 51.4 \\
b130 & Energy and drive functions & 50.7 \\
b152 & Emotional functions & 37.3 \\
b164 & Higher-level cognitive functions & 30.9 \\
b730 & Muscle power functions & 28.1 \\
b280 & Sensations of pain & 27.4 \\
b455 & Exercise tolerance functions & 26.7 \\
b117 & Intellectual functions & 25.3 \\
b140 & Attention functions & 20.4 \\
b134 & Sleep functions & 14.7 \\
b122 & Global psychosocial function & 11.9 \\
b180 & Experience of self and time functions & 11.9 \\
b760 & Control of voluntary movement functions & 11.9 \\
b156 & Perceptual functions & 9.8 \\
b160 & Thought functions & 9.8 \\
b710 & Mobility of joint functions & 9.8 \\
b144 & Memory functions & 9.1 \\
b167 & Mental functions of language & 7.7 \\
b210 & Seeing functions & 7 \\
b230 & Hearing functions & 7 \\
b440 & Respiration functions & 5.6 \\
b620 & Urination functions & 5.6 \\
\hline & &
\end{tabular}

Table 4 Body structures $(\mathrm{N}=13)$ (included were only those categories mentioned by at least $5 \%$ of the respondents)

\begin{tabular}{lll}
\hline $\begin{array}{l}\text { ICF } \\
\text { code }\end{array}$ & Title & $\begin{array}{l}\text { Percentage } \\
(\%)\end{array}$ \\
\hline s730 & Structure of upper extremity & 33.8 \\
s750 & Structure of lower extremity & 32.3 \\
s760 & Structure of trunk & 31.6 \\
s110 & Structure of brain & 30.2 \\
s710 & Structure of head and neck region & 19.0 \\
s720 & Structure of shoulder region & 17.6 \\
s770 & Additional musculoskeletal structures related & 14.7 \\
& to movement & 9.8 \\
s220 & Structure of eyeball & 9.1 \\
s120 & Spinal cord and related structures & 7.7 \\
s410 & Structure of cardiovascular system & 6.3 \\
s250 & Structure of middle ear & 6.3 \\
s260 & Structure of inner ear & 5.6 \\
s430 & Structure of respiratory system & \\
\hline
\end{tabular}

and examine factors surrounding VR and this study benefits from the ICF language and its cross-setting application. We conducted a worldwide survey of experts who are involved in VR. We asked questions on what are the important
Table 5 Activities and participation $(\mathrm{N}=36$ ) (included were only those categories mentioned by at least $5 \%$ of the respondents)

\begin{tabular}{|c|c|c|}
\hline $\begin{array}{l}\text { ICF } \\
\text { code }\end{array}$ & Title & $\begin{array}{l}\text { Percentage } \\
(\%)\end{array}$ \\
\hline d850 & Remunerative employment & 35.2 \\
\hline $\mathrm{d} 855$ & Non-renumerative employment & 28.1 \\
\hline $\mathrm{d} 475$ & Driving & 23.9 \\
\hline d920 & Recreation and leisure & 23.9 \\
\hline $\mathrm{d} 240$ & $\begin{array}{l}\text { Handling stress and other psychological } \\
\text { demands }\end{array}$ & 23.2 \\
\hline $\mathrm{d} 470$ & Using transportation & 22.5 \\
\hline d570 & Looking after one's health & 18.3 \\
\hline $\mathrm{d} 640$ & Doing housework & 18.3 \\
\hline d5 510 & Washing oneself & 14.7 \\
\hline $\mathrm{d} 230$ & Carrying out daily routine & 14.1 \\
\hline $\mathrm{d} 845$ & Acquiring, keeping and terminating a job & 13.3 \\
\hline d620 & Acquisition of goods and services & 12.6 \\
\hline d630 & Preparing meals & 12.6 \\
\hline d540 & Dressing & 11.9 \\
\hline d440 & Fine hand use & 11.2 \\
\hline $\mathrm{d} 450$ & Walking & 11.2 \\
\hline d520 & Caring for body parts & 10.5 \\
\hline $\mathrm{d} 410$ & Changing basic body position & 9.8 \\
\hline $\mathrm{d} 430$ & Lifting and caring objects & 9.8 \\
\hline $\mathrm{d} 455$ & Moving around & 9.8 \\
\hline d910 & Community life & 9.1 \\
\hline $\mathrm{d} 750$ & Informal social relationships & 8.4 \\
\hline d760 & Family relationships & 8.4 \\
\hline $\mathrm{d} 415$ & Maintaining a body position & 7.7 \\
\hline $\mathrm{d} 710$ & Basic interpersonal interactions & 7.7 \\
\hline d720 & Complex interpersonal interactions & 7.7 \\
\hline $\mathrm{d} 210$ & Undertaking a single task & 7 \\
\hline d660 & Assisting others & 7 \\
\hline d860 & Basic economic transactions & 7 \\
\hline $\mathrm{d} 170$ & Writing & 6.3 \\
\hline d 330 & Speaking & 6.3 \\
\hline $\mathrm{d} 350$ & Conversation & 6.3 \\
\hline $\mathrm{d} 770$ & Intimate relationships & 6.3 \\
\hline d166 & Assisting others & 5.6 \\
\hline d530 & Toiletting & 5.6 \\
\hline $\mathrm{d} 740$ & Formal relationships & 5.6 \\
\hline
\end{tabular}

factors that need to be considered in VR and linked the factors to the ICF so it can be meaningful to ICF users. We found that there is a multitude of ICF functioning domains based on the experts' responses which indicates further the complexity and breadth of VR as a field of research and practice.

The experts' perspective has been documented and reported in the literature [17-21]. Information gathered from the experts in the area provides a unique and rich 
Table 6 Environmental factors $(\mathrm{N}=30)$ (included were only those categories mentioned by at least $5 \%$ of the respondents)

\begin{tabular}{|c|c|c|}
\hline ICF Code & Title & Percentage $(\%)$ \\
\hline e310 & Immediate family & 40.8 \\
\hline e580 & Health services, systems and policies & 38.7 \\
\hline e590 & Labour and employment services, systems and policies & 37.3 \\
\hline e315 & Extended family & 36.6 \\
\hline e330 & People in positions of authority & 26.7 \\
\hline e165 & Assets & 24.6 \\
\hline e540 & Transportation services, systems and policies & 23.2 \\
\hline e570 & Social security services, systems and policies & 23.2 \\
\hline e325 & Acquaintances, peers colleagues, neighbours and community members & 21.8 \\
\hline e355 & Health professionals & 20.4 \\
\hline e150 & Design, construction and building products and technology for public use & 18.3 \\
\hline e155 & Design, construction and building products and technology for private use & 17.6 \\
\hline e430 & Individual attitudes of people in positions of authority & 17.6 \\
\hline e135 & Products and technology for employment & 16.2 \\
\hline e110 & Products or substances for personal consumption & 15.4 \\
\hline $\mathrm{e} 425$ & Individual attitudes of acquaintances, peers colleagues, neighbours & 15.4 \\
\hline e120 & Products and technology for personal indoor and outdoor mobility & 14.7 \\
\hline $\mathrm{e} 340$ & Personal care providers and personal assistants & 14.7 \\
\hline e410 & Individual attitudes of immediate family members & 14 \\
\hline $\mathrm{e} 320$ & Friends & 13.3 \\
\hline e415 & Individual attitudes of extended family members & 12.6 \\
\hline e550 & Legal services, systems and policies & 11.9 \\
\hline $\mathrm{e} 460$ & Societal attitudes & 9.9 \\
\hline e585 & Education and training services, systems and policies & 9.8 \\
\hline e360 & Health-related professions & 9.1 \\
\hline e115 & Products and technology for personal use in daily living & 8.4 \\
\hline e575 & General social support services, systems and policies & 8.4 \\
\hline $\mathrm{e} 450$ & Individual attitudes of health professionals & 7.7 \\
\hline e565 & Economic services, systems and policies & 7 \\
\hline $\mathrm{e} 525$ & Housing services, systems and policies & 5.6 \\
\hline
\end{tabular}

source of knowledge to understand workers with disability. This knowledge will further be useful for health care providers and clinical researchers.

The experts who have participated in this survey had different backgrounds. They came from 47 different countries, a fact which contributed to the multicultural and multinational perspective. This characteristic would also have an important implication in terms of possible applicability of this study to other settings. While it is remarkable that experts from all six WHO regions participated in this study, it is interesting to note that most of them came from developed regions such as Europe (primarily Western Europe), the Americas (primarily USA and Canada), and Western Pacific (primarily Australia). There is a great imbalance of the number experts from the different regions (only 12 out of the 151 experts, were from the WHO regions of Africa, Eastern Mediterranean, and Southeast Asia). The practice of VR could be more established in developed nations where VR infrastructure is in place, relative to developing or undeveloped nations. Indeed, VR services and its way of delivery vary even among developed countries [22, 23] due to difference in system and politics. The variation between world regions could be associated with variation in the availability of established health, economic, labor, and social systems that may be able to provide vocational rehabilitation services.

The respondents had different professions bringing their own unique and shared experience either into a unidisciplinary or interdisciplinary VR setting. This finding gives an indication of broad scope of VR given the different disciplines to address return to work or increasing work participation. Most of the respondents were therapists (physical or occupational therapist). However, we learned that different professionals from some countries have different scope of practice in providing VR. In South Africa, physical therapists usually do not see patients for VR but occupational therapists do. A high proportion of respondents represented the category "other professions". 
Looking closely at this category provides an insight as to how broad VR practice and research areas are-from movement science to sociology, public health, and health economics. Since our recruitment for experts was inclusive rather than exclusive, we were not surprised to find a variety of different fields of VR practice-from experts who directly manage patients to those engaged in clinical trials, teaching, and management. Given the multidisciplinary practice of $\mathrm{VR}$, it is likely that experts do crossover from one setting to the other within the same period (e.g. treating patients and teaching at a university).

The level of experience of the respondents was remarkable-the majority of them have 8 years of experience at a minimum, which gives credible weight to their input on the study. Moreover, a majority of the respondents rated themselves high in terms of their expertise in the field of VR. Our sample represented a good variety of experts who provide direct care to patients and those who work in research or administration-two perspectives that are essential.

The health conditions most commonly treated or researched by our respondents were musculoskeletal, mental, and neurologic health conditions. This finding is indicative of the high prevalence and great socioeconomic burden that these health conditions (alone or in coexistence) pose on patient level [24-27].

The diverse characteristics of the respondents were also evident in terms of the VR services or programs they are engaged with. Although the list of VR services was not exhaustive, it gave us an indication of the complexity and breadth of VR. Data on "other VR services" was collected to ensure that the full spectrum of services possible was covered which provided us additional information on VR services such as consultation, caregiver training and work and home management.

The experts' perspective based on this survey covered all four classifiable components of the ICF: body functions, body structures, activities and participation, and environmental factors. Of these components, activities and participation represented the most categories followed by environmental factors and body functions. The least representation could be found by body structures categories. This finding signifies a broad societal perspective rather than a sole consideration for the individual structure-level alone. This broad representation of the ICF components was found to be essential if VR or a return-to-work were to be successful [28-31].

The ICF categories selected based on the expert survey is reflective of VR as a multifaceted and multifactorial process. Work resumption as a function of work status is a common indicator of VR success [3, 32-34]. In the component activities and participation, therefore, it was not unsurprising to find remunerative or gainful employment (d850 remunerative employment) being the most frequently mentioned category. Other work-relevant categories were d845 acquiring, keeping and terminating a job, d240 handling stress and other psychological demands (perhaps applicable to mental-type of health conditions or jobs that demand mental competency), and $d 440$ fine hand use and d430 lifting and carrying objects (perhaps applicable to physical-type of health conditions or jobs that demand physical skills). On a different note, non-remunerative (non-paid) employment categories (d855 non-remunerative employment) such as volunteering were considered important along with 2920 recreation and leisure, d640 doing housework, d230 carrying out daily routine which are not necessarily traditional work domains. This evidence on work and non-work factors relevant to VR is essential in understanding work disability in general and in the delivery of successful VR [31]. Further, it supports the notion that "employment" or work does not necessarily have to be paid to be considered as such.

With regard to categories from the component environmental factors, it was evident that support from people surrounding the worker is essential. This support may come from family members (e310 immediate family, e315 extended family), boss or employer (e330 people in positions of authority), and co-workers (e325 acquaintances, peers, colleagues, neighbours and community members). This finding is consistent with the role that support and relationship play as part of one's social environment [8, 34]. The physical and at times political environment does play a crucial role in facilitating work participation [35-37]. Support from health care services and providers (e580 health services, systems and policies and e355 health professionals), labour services and providers (e590 labour and employment services, systems and policies), and social security services and providers (e570 social security services, systems and policies) was also considered by the respondents to be essential. These services related to health, labour, and social security appear to be the "trifecta" in facilitating work participation. Within the context of remuneration, assets (e165) in form of money, income, salary, or benefits could indeed facilitate or sustain return to work [8]. Other physical infrastructures were also observed such as transportation (e540 transportation services, systems and policies), building accessibility (e150 design, construction and building products and technology for public use and e155 design, construction and building products and technology for private use), and the workplace (e135 products and technology for employment).

The categories under the body functions component of the ICF lend its applicability to different kinds of health conditions and types of work, either physical or mental, or a combination of both. Mental health-related categories that were evident from the experts' responses include $b 126$ 
temperament and personality functions, b164 higher-level cognitive functions, b117 intellectual functions, and b140 attention functions as examples. Physical health conditionrelated categories included b730 muscle power functions, b760 control of voluntary movement functions, and $b 710$ mobility of joint functions, as examples. On one hand, there might be VR factors that are relevant across health conditions but may have varying effects or influence depending on whether it is mental or musculoskeletal condition in nature [34]. On the other hand, in some VR participants with certain health conditions and job types, both mental and physical-relevant categories may be applicable.

The respondents also included several categories from the body structures component that were important in VR. A few items but a comprehensive list included structures that were relevant to mental, musculoskeletal, and neurologic health conditions that appeared to be consistent with type of health conditions the respondents commonly deal with. These structures included brain (s110 structure of brain), back and extremities ( 5730 structure of upper extremity, s750 structure of lower extremity, and s760 structure of trunk). Also included were structures of special senses such as the eye ( 220 structure of eyeball) and ear ( 250 structure of middle ear and s260 structure of inner ear). This coverage reflects the broad spectrum of diseases in VR settings that experts encounter.

We did not make a separate analysis for inter-country or-region difference of responses. We assumed that the ICF functioning domains operate regardless of country, region, or setting. We suspect, however, that there might be variation at the granular level of the systems, politics, governance, social environment, and services-which overall may still be similar in ICF terms but whose operationalization may be different. Nevertheless, the "conceptualization" of the different domains in different countries may not be different, in our opinion.

With regards to our linking methodology, there was not only a satisfactory agreement between the linkers but the agreement also exceeded chance. This shows that the linking procedure was reliable in this study.

We do recognize the limitations of this study. First, the results could not be generalizable to all experts' perspectives on VR. While there was high response rate, it is possible that some experts who have been contacted did not receive the invitation due to incorrect e-mail addresses, or that experts from some developing nations do not have access to e-mail technology hence, were not included in the initial pool to begin with. Further, only those experts who were competent in the English language (self-reported) were included which could lead to selection bias. Secondly, the responses to the survey were not verified for possible misclassification because they were all self-reported. Thirdly, different countries have different means of VR so for example, only physical therapists are allowed to provide VR or VR services are provided for physical health conditions only and not for mental conditions. Fourthly, the type of VR services that the experts were involved with were not exhaustive. Thus, it is possible that VR encompasses more services than what was given as options in the questions to the respondents, although the category "Other" was provided as a choice. While this is not the main objective of this study, information relating to VR practices may provide insight to the variety of services provided under VR in different countries and, as such, may indicate the scope of VR and the professionals who provide it. Closely examining the category "Other" revealed some redundancy with VR services that were already specified. Finally, our study does not provide ways on "how" to measure the ICF categories. We feel that this is a critical next step if we are to operationalize the ICF categories in actual VR setting.

\section{Conclusions}

Our findings support the wide array of factors on functioning domains, from the experts' perspective, that need to be considered in VR practice and research. This study has provided us with a list of ICF categories that were considered to be important in the VR process by expert respondents and which can help advance our understanding of the factors towards successful outcome. We encourage the VR community to further examine the list of variables provided here. Validation studies are needed in the near future to look at the utility of the categories in interprofessional communication (i.e. health care providers), service provision and reimbursement, and health information record.

Acknowledgments The authors would like to thank Dr. Teresa Brinkel, Veronika Lay, Miriam Lückenkemper, Andrea Pfingsten, and Wolfgang Segerer for providing technical consultation and help during the conduct of the study. Special thanks to Cristina Bostan, who is supported by a Marie Curie Fellowship from the EU funded project MURINET, the ICF Research Branch and the Swiss Paraplegic Research in Nottwil, Switzerland. This project was funded by the Swiss Accident Insurance Company (SUVA).

\section{References}

1. Khan F, Ng L, Turner-Stokes L. Effectiveness of vocational rehabilitation intervention on the return to work and employment of persons with multiple sclerosis. Cochrane Database Syst Rev. 2009;1(1):CD007256.

2. Lysaker PH, Davis LW, Bryson GJ, Bell MD. Effects of cognitive behavioral therapy on work outcomes in vocational rehabilitation for participants with schizophrenia spectrum disorders. Schizophr Res. 2009;107(2-3):186-91. 
3. Suoyrjo H, Oksanen T, Hinkka K, Kivimaki M, Klaukka T, Pentti $\mathrm{J}$, et al. The effectiveness of vocationally oriented multidisciplinary intervention on sickness absence and early retirement among employees at risk: an observational study. Occup Environ Med. 2009;66(4):235-42.

4. Marini I, Lee GK, Chan F, Chapin MH, Romero MG. Vocational rehabilitation service patterns related to successful competitive employment outcomes of persons with spinal cord injury. J Vocat Rehabil. 2008;28(1):1-13.

5. Dutta A, Gervey R, Chan F, Chou CC, Ditchman N. Vocational rehabilitation services and employment outcomes for people with disabilities: a United States study. J Occup Rehabil. 2008;18(4): 326-34.

6. Crowther R, Marshall M, Bond G, Huxley P. Vocational rehabilitation for people with severe mental illness. Cochrane Database Syst Rev. 2001;2(2):CD003080.

7. World Health Organization (2008) International classification of functioning, disability, and health. Available from: http://www.w ho.int/classifications/icf/site/icftemplate.cfm.

8. Young AE. Return to work following disabling occupational injury-facilitators of employment continuation. Scand J Work Environ Health. 2010;36(6):473-83.

9. Lagerveld SE, Bultmann U, Franche RL, van Dijk FJ, Vlasveld MC, van der Feltz-Cornelis CM, et al. Factors associated with work participation and work functioning in depressed workers: a systematic review. J Occup Rehabil. 2010;20(3):275-92.

10. Homa DB. Using the international classification of functioning, disability and health (ICF) in job placement. Work. 2007;29(4):277-86.

11. Wasiak R, Young AE, Roessler RT, McPherson KM, van Poppel MN, Anema JR. Measuring return to work. J Occup Rehabil. 2007; 17(4):766-81.

12. Escorpizo R, Ekholm J, Gmünder HP, Cieza A, Kostanjsek N, Stucki G. Developing a core set to describe functioning in vocational rehabilitation using the international classification of functioning, disability, and health (ICF). J Occup Rehabil. 2010;20(4): 502-11.

13. Cieza A, Geyh S, Chatterji S, Kostanjsek N, Ustun B, Stucki G. ICF linking rules: an update based on lessons learned. J Rehabil Med. 2005;37(4):212-8.

14. Cohen J. A coefficient of agreement for nominal scales. Educ Psychol Meas. 1960;20:37-46.

15. Efron B. The jack knife, the bootstrap and other resampling plans. Philadelphia PA: Society for industrial and applied mathematics; 1982.

16. Vierkant RA. A SAS macro for calculating bootstrapped confidence intervals about a kappa coefficient. Available from: http:// www2.sas.com/proceedings/sugi22/STATS/PAPER295.PDF 2009.

17. Scheuringer M, Kirchberger I, Boldt C, Eriks-Hoogland I, Rauch $\mathrm{A}$, Velstra IM, et al. Identification of problems in individuals with spinal cord injury from the health professional perspective using the ICF: a worldwide expert survey. Spinal Cord. 2010;48(7): 529-36

18. Spoto MM, Collins J. Physiotherapy diagnosis in clinical practice: a survey of orthopaedic certified specialists in the USA. Physiother Res Int. 2008;13(1):31-41.

19. Lemberg I, Kirchberger I, Stucki G, Cieza A. The ICF core set for stroke from the perspective of physicians: a worldwide validation study using the Delphi technique. Eur J Phys Rehabil Med. 2010; 46(3):377-88

20. Lakeman R. Mental health recovery competencies for mental health workers: a Delphi study. J Ment Health. 2010;19(1):62-74.
21. Turton P, Wright C, White S, Killaspy H. DEMoBinc group. Promoting recovery in long-term institutional mental health care: an international Delphi study. Psychiatr Serv. 2010;61(3):293-9.

22. Stubbs J, Deaner G. When considering vocational rehabilitation: describing and comparing the Swedish and American systems and professions. Work. 2005;24(3):239-49.

23. Muijzer A, Groothoff JW, de Boer WE, Geertzen JH, Brouwer S. The assessment of efforts to return to work in the European Union. Eur J Public Health. 2010;20(6):689-94.

24. Patten SB, Williams JV, Wang J. Mental disorders in a population sample with musculoskeletal disorders. BMC Musculoskelet Disord. 2006;7:37.

25. Wang J, Adair CE, Patten SB. Mental health and related disability among workers: a population-based study. Am J Ind Med. 2006; 49(7):514-22.

26. United States Joint and Bone Decade. The burden of musculoskeletal diseases in the United States. Available from: http://www. boneandjointburden.org/. 2008.

27. World Health Organization. The burden of musculoskeletal conditions at the start of the new millenium. WHO technical report series 919. 2003.

28. Sandqvist JL, Henriksson CM. Work functioning: a conceptual framework. Work. 2004;23(2):147-57.

29. Sanderson K, Nicholson J, Graves N, Tilse E, Oldenburg B. Mental health in the workplace: using the ICF to model the prospective associations between symptoms, activities, participation and environmental factors. Disabil Rehabil. 2008;30(17): 1289-97.

30. Kirsh B, Cockburn L, Gewurtz R. Best practice in occupational therapy: program characteristics that influence vocational outcomes for people with serious mental illnesses. Can J Occup Ther. 2005;72(5):265-79.

31. Kirsh B, Krupa T, Cockburn L, Gewurtz R. A Canadian model of work integration for persons with mental illnesses. Disabil Rehabil. 29 Mar 2010.

32. Luk KD, Wan TW, Wong YW, Cheung KM, Chan KY, Cheng $\mathrm{AC}$, et al. A multidisciplinary rehabilitation programme for patients with chronic low back pain: a prospective study. J Orthop Surg. 2010;18(2):131-8.

33. Bultmann U, Sherson D, Olsen J, Hansen CL, Lund T, Kilsgaard J. Coordinated and tailored work rehabilitation: a randomized controlled trial with economic evaluation undertaken with workers on sick leave due to musculoskeletal disorders. J Occup Rehabil. 2009;19(1):81-93.

34. Brouwer S, Reneman MF, Bultmann U, van der Klink JJ, Groothoff JW. A prospective study of return to work across health conditions: perceived work attitude, self-efficacy and perceived social support. J Occup Rehabil. 2010;20(1):104-12.

35. Sweetland J, Riazi A, Cano SJ, Playford ED. Vocational rehabilitation services for people with multiple sclerosis: what patients want from clinicians and employers. Mult Scler. 2007; 13(9):1183-9.

36. Carpenter C, Forwell SJ, Jongbloed LE, Backman CL. Community participation after spinal cord injury. Arch Phys Med Rehabil. 2007;88(4):427-33.

37. Jongbloed L, Backman C, Forwell SJ, Carpenter C. Employment after spinal cord injury: the impact of government policies in Canada. Work. 2007;29(2):145-54. 